\title{
Estudo da Toxicidade de Formulações Fitoterápicas Emagrecedoras Utilizando Bioensaio com Allium cepa
}

\author{
Kaégilla Reis Silva ${ }^{1}$, Larissa Costa Silva Fogaça².
}

Resumo: $\mathrm{O}$ uso indiscriminado de fitoterápicos e plantas medicinais, por serem naturais, pode acarretar em graves consequências, como reações alérgicas, toxicidade e até interações medicamentosas, caso haja a automedicação. Diante disto, objetivou-se com o presente estudo determinar a toxicidade de formulações fitoterápicas, comercializados em casas de medicamentos naturais, a partir do bioensaio com Allium cepa. Foram avaliados os chás de hibisco (Hibiscus rosa-sinensis), cavalinha (Equisetum giganteum L.), verde (Camellia sinensis) e folha de amora (Morus alba), em diferentes concentrações 12,5, 62, $125 \mathrm{~g} / \mathrm{L}$, e o controle negativo, pela observação do crescimento das raízes das cebolas submersas nas amostras de chás. Os ensaios demostraram que o chá de hibisco apresentou menor toxicidade, em contrapartida os bulbos de A. cepa em contato com os chás de cavalinha e amora obtiveram menor comprimento de raízes, não diferindo estatisticamente, pelo Teste Tukey a 5\% de probabilidade. O estudo das concentrações demonstrou que os chás verde e cavalinha apresentam inibição ao crescimento com o aumento das concentrações destes. Os resultados indicam que os são necessários estudos mais detalhados a respeito da toxicidade em altas concentrações destes fitoterápicos, entretanto recomenda-se que estes sejam utilizados com moderação.

Palavras-chave: Chás emagrecedores; Teste de toxicidade; Bioensaio Allium cepa.

\section{Toxicity study of Herbal formulations for Weight loss using Bioassay with Allium cepa}

\begin{abstract}
: he indiscriminate use of herbal and medicinal plants, because they are natural, can lead to serious consequences, such as allergic reactions, toxicity and even drug interactions, if there is self-medication. Therefore, the objective of this study was to determine the toxicity of herbal formulations, marketed in natural medicine houses, from the bioassay with Allium cepa. Hibiscus (rosa-sinensis), horsetail (Equisetum giganteum L.), green (Camellia sinensis) and mulberry leaf (Morus alba) were evaluated in different concentrations 12.5, 62, $125 \mathrm{~g} / \mathrm{L}$, and the negative control, by observation of root growth of the submerged onions in the tea samples. The tests showed that the hibiscus tea had lower toxicity, in contrast the bulbs of A. cepa in contact with the mackerel and blackberry teas obtained lower root length, not statistically different, by the Tukey test at $5 \%$ probability. Concentration studies have shown that green and horsetail teas exhibit growth inhibition with increasing concentrations of these. The results indicate that more detailed studies are required regarding the toxicity in high concentrations of these phytotherapics, however it is recommended that these be used in moderation.
\end{abstract}

Keywords: Slimming teas; Toxicity test; Bioassay Allium strain. ${ }^{1}$ Graduanda do curso de Farmácia pela Faculdade Independente do Nordeste - FAINOR. kaegilla_kaka@ hotmail.com.
${ }^{2}$ MSc. em Engenharia de Alimentos - Professora do Colegiado de Farmácia - FAINOR. larissacosta@ @ainor.com.br 


\section{Introdução}

Desde a antiguidade as plantas medicinais são utilizadas no tratamento de doenças, apresentando-se como um método terapêutico eficaz utilizado pela população. Hipócrates marcado como o pai da medicina grafou em sua obra Corpus Hipocrático o tratamento com extrato vegetal para cada doença o que se fez uma pratica mundial na utilização dessas plantas. Esse método curativo vem sendo utilizados no tratamento de várias doenças como obesidade, hipertensão, diabete e dores em geral. (GELATTI; LIVEIRA; COLET, 2016).

Segundo a Agência nacional de Vigilância Sanitária - ANVISA (2012), as plantas medicinais exercem papel de remédios eficazes no alivio e até mesmo na cura de enfermidades. Por outro lado, as informações acerca do potencial toxicológico e mutagênico de muitas das plantas utilizadas, ainda são escassas. (LOPES et al., 2011)

A utilização de plantas medicinais no tratamento da obesidade tornou se um fator de imensa preocupação para pesquisadores e estudiosos. Nos últimos anos os relatos de reações adversas devido ao uso de plantas medicinais aumentaram em uma grande proporção (LOPES et al., 2011). A utilização de fitoterápicos sem orientação medica não é aconselhável, principalmente em mulheres grávidas podendo provocar danos ao feto, problemas embriotóxicos, teratogênicos e até mesmo ao aborto (RODRIGUES et al., 2011).

A obesidade considerada como um problema de saúde pública gera na população uma busca incessante por meios que sejam mais facilmente adaptáveis à sua rotina, principalmente o uso de substâncias consideradas emagrecedoras. Neste contexto destacam-se os produtos vegetais, que são considerados como produtos seguros pelo fato de serem naturais e podem ser muitas vezes encontrados em farmácias e casas naturais na forma de fitoterápicos e chás emagrecedores. (PADILHA et al., 2013).

Alternativas naturais na busca de resultados satisfatórios no processo de emagrecimento ganharam grande destaque na sua utilização pela população. Alguns fatores podem explicar essa ocorrência como o desenvolvimento sobre os produtos fitoterápicos descrevendo sua eficácia e segurança, e a tendência em procurar terapias menos agressivas. (BIESKI, 2013)

A fitoterapia segundo o Ministério da Saúde é a prática da utilização de plantas com fins terapêuticos, presentes no mercado em várias formas farmacêuticas principalmente na apresentação de chás. (ARAUJO; PENA; FREITAS, 2015). Nesse contexto vale ressaltar que 
os chás no Brasil são considerados como alimento e não como medicamento, essa formulação não tem registro na Anvisa. Portanto o farmacêutico deve orientar a população sobre a automedicação e os seus riscos à saúde. (RODRIGUES et al., 2011).

O chá fitoterápico mais utilizado pela população tem ganhado grande atenção por conta de seus benefícios à saúde, baixo custo e facilidade de acesso; no entanto, são usados muitas vezes sem nenhuma comprovação científica, podendo causar efeitos toxicológicos à população. As toxicidades das plantas medicinais podem gerar vários problemas à saúde do indivíduo, modificações metabólicas e vários distúrbios no organismo. A intoxicação causada pelas plantas medicinais é clinicamente difícil de obter um diagnóstico preciso. (OLIVEIRA; MAYWALD; ROSA, 2013).

O teste allium cepa é utilizado como um bioensaio toxicológico na avaliação do potencial de infusões medicinais em chás, na análise do potencial citotóxico e mutagênico. Essa análise é realizada através de avaliações de células meristemáticas provenientes da ponta da raiz. Para a escolha do método devem ser considerados os seguintes requisitos: sensibilidade, simplicidade e reprodutibilidade. Dessa forma, este teste é viável, devido as suas raízes estarem em contato direto com a substância a ser analisada. (BELCAVELLO et al., 2012).

O teste de Allium cepa vem sendo uma opção de análise eficaz e barata proporcionando resultados para avaliação de alterações cromossômicas e mitóticas, além do episódio de inibição da divisão celular por conta dos elementos presentes nas plantas. Esse teste é utilizado para verificação das características físicas como tamanho da raiz, alteração de cor, característica microscópica e formato (FRESCURA, 2012).

Neste contexto, objetivou-se com este trabalho o estudo da toxicidade de quatro formulações fitoterápicas, indicados para auxiliar no emagrecimento, comercializados em casas de medicamentos naturais, a partir do bioensaio com Allium cepa, com o intuito de assegurar a utilização dos mesmos, contribuindo cientificamente com a melhoria da qualidade de vida da população.

\section{Metodologia}

O bioensaio com Allium cepa é um método de baixo custo e alta eficiência na detecção de toxicidade em determinados produtos (SILVA, et al., 2015). O experimento foi realizado 
nos laboratórios de Química e Microbiologia da Faculdade Independente do Nordeste - Fainor e as amostras de chás emagrecedores foram coletadas no comércio de Vitória da Conquista Bahia, em lojas especializadas em produtos naturais. Os bulbos de Allium cepa foram adquiridos de fonte comercial, no Centro de Abastecimento de Vitória da Conquista mantendo o cuidado de selecionar um material com qualidade adequada para o experimento, utilizando cinco bulbos para cada tratamento, adequadamente higienizados.

Foram utilizadas amostras de chás de hibisco (Hibiscus rosa-sinensis), cavalinha (Equisetum giganteum L.), verde (Camellia sinensis) e folhas de amora (Morus alba) . As formulações fitoterápicas a serem avaliadas foram colocadas em infusão em água destilada, nas concentrações: T1: 12,5 g/L (concentração recomentada para o uso) ; T2: 62 g/L ; T3: 125 g/L e o controle negativo, com apenas água destilada, e após ebulição, deixadas em repouso por 10 minutos. Posteriormente foram coadas com o auxílio de uma peneira e ao atingir temperatura ambiente foram transferidos para cálices de sedimentação. Foram utilizadas vinte cebolas para cada tratamento, espetadas em palito de madeira para que ficassem suspensas no cálice e com a raiz em contato com a infusão. Todos os tratamentos ficaram imersos por 48 horas. Após este tempo, com auxílio de uma régua foi medido o comprimento das raízes de cada bulbo avaliando-se o enraizamento dos bulbos de Allium cepa, conforme metodologia de Fiskesjö (1985) adaptada por Barbério et al. (2011).

As análises foram realizadas em quintuplicata e cada tratamento foi comparado com o controle negativo e a ocorrência de toxicidade foi considerada a partir da inibição do crescimento das raízes. Os resultados foram avaliados pela realização da análise estatística ANOVA. As amostras de chás tiveram suas médias comparadas pelo teste Tukey a 5\% de probabilidade e os resultados para as diferentes concentrações das amostras de chá foram submetidos à análise de regressão ao nível de 5\% de probabilidade, utilizando o programa estatístico SAEG 9.1.

\section{Resultados e Discussão}

Os resultados para a avaliação da toxicidade de chás fitoterápicos utilizando o bioensaio de Allium cepa estão apresentados na tabela 1. 
Tabela 1 - Comprimento de raiz de cebola submetido a diferentes concentrações de chás. Chás Fitoterápicos Comprimento de raiz $(\mathrm{cm})$

$\begin{array}{cc}\text { Hibisco } & 1,135 \mathrm{a} \\ \text { Verde } & 0,805 \mathrm{~b} \\ \text { Cavalinha } & 0,425 \mathrm{c} \\ \text { lhas de Amora } & 0,395 \mathrm{c}\end{array}$

Médias seguidas pela mesma letra, na coluna, não diferem entre si pelo teste Tukey a 5\% de probabilidade.

Para os diferentes chás avaliados, observou-se que quando o chá de Hibisco foi aplicado, os bulbos de cebola apresentaram o maior comprimento de raiz, igual a 1,135 cm (Tabela 1). Esse maior desenvolvimento radicular dos bulbos está possivelmente associado a menor toxicidade do chá de hibisco em relação aos demais chás avaliados. Por outro lado, os chás de Cavalinha e Amora foram os que apresentaram maior toxicidade comprovada pelo menor comprimento de raízes nos bulbos de A. cepa, não diferindo entre si estatisticamente, a 5\% de probabilidade pelo teste Tukey.

Avaliando a toxicidade de preparações fitoterápicas utilizadas para emagrecimento, pelo mesmo método adotado nessa pesquisa, Andrade e Almeida (2015) observaram efeito fitotóxico dos chás de 7 ervas e de 30 ervas, pela redução do comprimento das raízes nos bulbos de Allium cepa. Os bulbos apresentaram comprimento de raízes igual a $0,78 \mathrm{~cm}$ para o chá de 7 ervas, enquanto que no tratamento controle, as raízes apresentaram 2,74 cm de comprimento. Nas preparações fitoterápicas tanto de 7 ervas quanto de 30 ervas, a Cavalinha era um dos componentes responsáveis pela fitoxicidade.

Em outro estudo, avaliando a toxicidade de infusões de chás de emagrecimento através do teste Allium cepa, Rocha et al. (2017) observaram que o chá verde (Camellia sinensis) induz toxicidade nas células de meristemas de A. cepa, como avaliado pela inibição de crescimento de raízes de forma altamente significante $(\mathrm{P}<0,0001)$ em todas as concentrações testadas, enquanto que o chá de hibisco, percebeu-se uma menor inibição no crescimento radicular, com menor grau de significância que o chá verde, corroborando com o presente estudo.

As diferentes concentrações aplicadas as amostra de chás fitoterápicos foram avaliadas estatisticamente por regressão e os resultados podem ser observados na figura 1. 


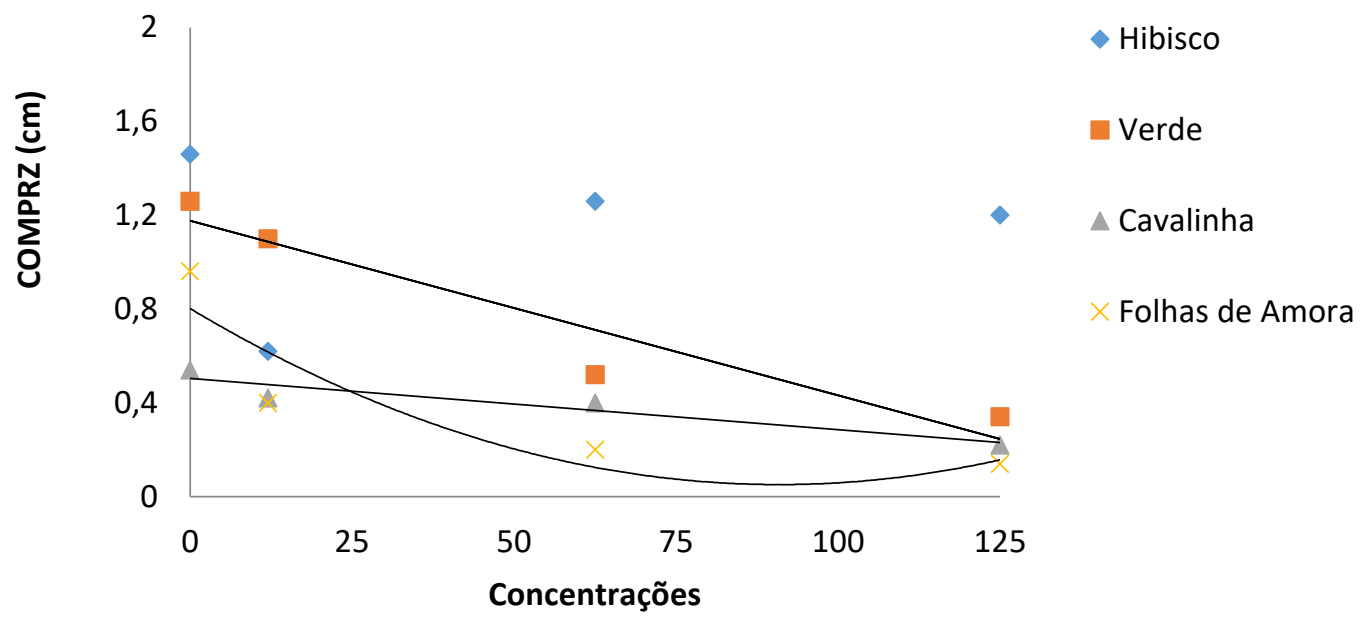

Hibisco: Não significativo.

Verde: $y=-0,0074 x+1,1763$

$\mathrm{R}^{2}=0,9112$

$\mathrm{R}^{2}=0,8889$

Cavalinha: $y=-0,0022 x+0,504$

Folhas de Amora: $y=9 \mathrm{E}-05 \mathrm{x}^{2}-0,0165 \mathrm{x}+0,8017 \quad \mathrm{R}^{2}=0,8138$

Figura 1. Efeito das concentrações dos chás fitoterápicos no comprimento das raízes dos bulbos de Allium cepa.

A análise de regressão para as diferentes concentrações avaliadas no chá verde e chá cavalinha foram significativas $(\mathrm{P} \leq 0,05)$ para o efeito linear decrescente (Figura 1), demonstrando que com o aumento das concentrações houve uma redução no crescimento das raízes dos bulbos de Allium cepa, podendo atribuir a estes, maior toxicidade em concentrações elevadas.

A planta Camelia sinensis, pertencente à família Theaceae, é conhecida popularmente por chá verde ou chá da Índia. Os flavonóides e as catequinas são os principais componentes químicos terapêuticos desta planta, sendo potentes antioxidantes, quelantes de metais e inibidores da lipoperoxidação (SCHMITZ et al., 2005), no entanto, em altas concentrações, principalmente a catequina, pode ser tóxica ao organismo, especialmente para o fígado.

Estudos de toxicidade e ensaios dos mecanismos utilizados pela cavalinha (Equisetum giganteum $\mathrm{L}$ ) não foram conclusivos a respeito da dose tóxica destes. A intoxicação aguda por tiaminase, principal composto tóxico de plantas da espécie Equisetum, é comprovada no gado equino (RIET-CORREA, RIET-CORREA e SCHILD, 2002), entretanto são necessários mais estudos a respeito da intoxicação em outros animais ou em humanos (MELLO e BUDEL, 2013). 
A análise das concentrações do chá de folhas de amora foi significativa $(\mathrm{P} \leq 0,05)$ para o efeito quadrático (Figura 1), com um valor mínimo de $0,053 \mathrm{~cm}$ do comprimento da raiz dos bulbos Allium cepa numa concentração de $90,59 \mathrm{~g} / \mathrm{L}$ das folhas de amora. Para o chá de hibisco a regressão não foi significativa, não havendo ajuste de modelo polinomial.

\section{Conclusão}

A análise dos resultados demonstra que o teste de toxicidade utilizando-se de bulbos de Allium cepa, apresentou-se como um método viável para tal avaliação, sendo este validado pelo Programa Internacional de Segurança Química e pelo Programa Ambiental das Nações Unidas (UNEP), de baixo custo, apresentando resultados satisfatórios. Os chás de folhas de amora e cavalinha apresentaram maior toxicidade com menor crescimento de raízes, alertando para um maior cuidado no consumo destes. O aumento das concentrações dos chás verde e de cavalinha apresentou maior toxicidade com redução do crescimento das raízes.

Os chás fitoterápicos comercializados em casas de produtos naturais devem ser utilizados com cautela, aos consumidores que o utilizam com fins estéticos, pois o seu uso indiscriminado, sem prescrição médica, pode acarretar em graves consequências a saúde da população. Com isso vale evocar que informações adquiridas de ensaios vegetais não devem ser conceituadas permanentes visto que a substância analisada pode apresentar efeitos adversos a cada tipo de organismo, sinalizando a necessidade de mais estudos relacionados a toxicidade desses chá tão comumente utilizados.

\section{Referências}

ANDRADE, A. C. de; ALMEIDA, R. B. de. Avaliação de toxicidade de preparações fitoterápicas utilizadas para emagrecimento. 2015, $20 \mathrm{f}$. Monografia (Bacharel em Farmácia) Faculdade de Pindamonhagaba - FUNVIC, Pindamonhagaba-SP, 2015.

ARAÚJO, Manuela Souza Correia de et al. A utilização de plantas medicinais e da fitoterapia em comunidades assistidas pela Estratégia Saúde da Família. Rev. Bras. Pesq. Saúde, Vitória, v. 17 , n. 4,2015 , p. 6-16. 
BARBÉRIO, A.; VOLTOLINI, J. C.; MELLO, M. L. S. Standardization of bulb and root sample sizes for the Allium cepa test. Ecotoxicology, v. 20, n. 4, p. 927-935, 2011.

BELCAVELlO, L.; CUNHA, M. R. H.; ANDRADE, M. A.; BATITUCCI, M. D. C. P. Citotoxicidade e danos ao DNA induzidos pelo extrato de Zornia diphylla, uma planta medicinal. Natureza on line, v. 10, n. 3, p. 140-145, 2012.

BIESKI, I.G.C. Plantas medicinais e aromáticas no Sistema Único de Saúde da Região Sul de Cuiabá - MT. Secretaria Municipal de Saúde de Cuiabá - MT. 92 fl. Monografia (Especialização em Plantas Medicinais). Universidade Federal de Lavras, Lavras, MG. 2013.

FISKESJÖ, G. The Allium test as a standard in environmental monitoring. Hereditas, v. 102, n. 1, p. 99-112, 1985.

FRESCURA, V. D. S. Avaliação do potencial antiproliferativo, genotóxico e antimutagênico das espécies Psychotria brachypoda (Müll. Arg.) Briton e Psychotria birotula Smith \& Downs (Rubiaceae). 2012. 74 f. Dissertação (Mestrado em Agrobiologia) Universidade Federal de Santa Maria. Santa Maria, RS.

GELATTI, G. T.; OLIVEIRA, K. R.; COLET, C. F. Potenciais interações relacionadas ao uso de medicamentos, plantas medicinais e fitoterápicos em mulheres no período do climatério. Revista de Pesquisa: Cuidado é Fundamental , [S.1.], v. 8, n. 2, 2016, p. 4328-4346.

LOPES G. A. D.; FELICIANO L. M.; DINIZ R. E. S.; ALVES M. Q. F. Plantas medicinais: indicação popular de uso no tratamento de hipertensão arterial sistêmica (has). Revista Ciência em Extensão, v. 6, n. 2, 143 -155, 2011.

MELLO M.; BUDEL, J. M. EQUISETUM L. (Equisetaceae): Uma revisão. Cadernos da Escola de Saúde. Curitiba, v. 1, n. 9, p. 1-15, 2013.

OLIVEIRA, E. M. A. MAYWALD, P. G. ROSA, G. A. Distribuição de plantas medicinais e fitoterápicos através do SUS. E_RAC - Encontro Anual de Ciências. v. 3, n. 1. 2013.

PADILHA et al. Termogênicos naturais na diminuição da obesidade e prevenção do diabetes mellitus tipo II. FSG. Faculdade da Serra Gaúcha. I Congresso de pesquisa e extensão. Caxias do Sul, 2013.

RIET-CORREA F.; RIET-CORREA G.; SCHILD A. Importância do exame clínico para o diagnóstico das enfermidades do sistema nervoso em ruminantes equídeos. Pesquisa Veterinária Brasileira, v. 22, n. 4, p.161-168, 2002.

ROCHA, L. S. S.; CABRAL, L. I. A.; PIO, P. B. de S.; OLIVEIRA, R. M. C.; COUTINHO, L. C.; ALMEIDA, D. M. P. F. de. Análise da toxicidade de infusões de chás de emagrecimento através do teste Allium cepa. Revista Biotecnologia \& Ciência, v.6, n.1, p.55-62, 2017.

RODRIGUES, H.G. et al . Efeito embriotóxico, teratogênico e abortivo de plantas medicinais. Revista Brasileira de Plantas Medicinais. Botucatu, v. 13, n. 3, p. 359-366, 2011. 
SCHMITZ, W.; SAITO, A. Y.; ESTEVÃO, D.; SARIDAKIS, H. O. O chá verde e suas ações como quimioprotetor. Semina, v. 26, n. 2, p. 119-130, 2005.

SILVA, V. H. F.; RIBEIRO, G. M. R.; GRIPP, R. S.; DUARTE, M. J. S.; LEOPOLDO, J. R.; BITTENCOURT, A. H. C.; AGOSTINHO, L. A. Determinação do potencial genotóxico, toxicidade, índice mitótico de boldo e utilização de plantas medicinais em região rural próxima ao município de Muriaé (MG). Revista Científica da FAMINAS, v. 11, n. 2, mai -ago, 2015.

\section{Como citar este artigo (Formato ABNT):}

SILVA, Kaégilla R.; FOGAÇA, Larissa C. S. Estudo da Toxicidade de Formulações Fitoterápicas Emagrecedoras Utilizando Bioensaio com Allium cepa. Id on Line Revista Multidisciplinar e de Psicologia, 2018, vol.12, n.40, p.1105-1113. ISSN: 1981-1179.

Recebido: 28.05.2018

Aceito: 29.05 .2018 